\title{
Enhanced Accumulation of Phosphorylated $\alpha$-Synuclein and Elevated $\beta$-Amyloid 42/40 Ratio Caused by Expression of the Presenilin-1 $\Delta$ T440 Mutant Associated with Familial Lewy Body Disease and Variant Alzheimer's Disease
}

\author{
Hiroyuki Kaneko, ${ }^{1,4}$ Akiyoshi Kakita, ${ }^{2}$ Kensaku Kasuga, ${ }^{1,4}$ Hiroaki Nozaki, ${ }^{1,4}$ Atsushi Ishikawa, ${ }^{6}$ Akinori Miyashita, ${ }^{3}$ \\ Ryozo Kuwano, ${ }^{3}$ Genta Ito, ${ }^{7}$ Takeshi Iwatsubo, ${ }^{7}$ Hitoshi Takahashi, ${ }^{5}$ Masatoyo Nishizawa, ${ }^{4}$ Osamu Onodera, ${ }^{1}$ \\ Sangram S. Sisodia, ${ }^{8}$ and Takeshi Ikeuchi ${ }^{1}$ \\ Departments of ${ }^{1}$ Molecular Neuroscience, ${ }^{2}$ Pathology Neuroscience, and ${ }^{3}$ Bioresource Science Branch, Center for Bioresources, and Departments of \\ ${ }^{4}$ Neurology and ${ }^{5}$ Pathology, Brain Research Institute, Niigata University, Niigata 951-8585, Japan, ${ }^{6}$ Department of Neurology, Brain Disease Center Agano \\ Hospital, Agano 959-2221, Japan, ${ }^{7}$ Department of Neuropathology and Neuroscience, Graduate School of Pharmaceutical Sciences, University of Tokyo, \\ Tokyo 113-0033, Japan, and ${ }^{8}$ Department of Neurobiology, The University of Chicago, Chicago, Illinois 60637
}

Mutations in the PSEN1 gene encoding presenilin 1 (PS1) are linked to a vast majority of pedigrees with early-onset, autosomal dominant forms of familial Alzheimer's disease (FAD). Lewy body (LB) pathology is frequently found in the brains of FAD patients harboring PSEN1 mutations. We recently reported on a novel PS1 mutation with the deletion of threonine at codon $440(\Delta \mathrm{T} 440)$ in a familial case diagnosed as having the neocortical type of dementia with LBs (DLB) and variant AD. In this report, we investigated the possible involvement of PS1 $\Delta$ T440 mutation in aberrant $\alpha$-synuclein accumulation. We established cell lines that stably express either wild-type (WT) PS1 or the FAD-linked PS1 H163R, E280A, $\Delta$ E9, and PS1 $\Delta$ T440 mutants and now demonstrate that the expression of the PS1 $\Delta$ T440 mutant led to a marked elevation in the ratio of $\beta$-amyloid $(\mathrm{A} \beta) 42 / 40$ peptides in a conditioned medium. More importantly, we report here that the levels of phosphorylated $\alpha$-synuclein increase in neuronal and non-neuronal cells expressing the PS1 $\Delta$ T440 mutant compared with cells that express WT PS1 or the PS1 H163R and E280A variants that are not associated with LB pathology. This finding is consistent with our demonstration of elevated levels of phosphorylated $\alpha$-synuclein in the detergent-resistant fraction prepared from a patient's brain with PS1 $\Delta$ T440 mutation. These observations raise the intriguing suggestion that the mechanism(s) by which the PS1 $\Delta$ T440 mutant causes $\mathrm{DLB}$ and variant $\mathrm{AD}$ are by enhancing the phosphorylation of $\alpha$-synuclein and the ratio of $\mathrm{A} \beta_{42 / 40}$ peptides, respectively, in the brain.

Key words: presenilin; $\alpha$-synuclein; $\beta$-amyloid; Lewy body; $\gamma$-secretase; variant Alzheimer's disease

\section{Introduction}

Mutations in the PSEN1 gene encoding presenilin 1 (PS1) are linked to a vast majority of pedigrees with early-onset, autosomal dominant forms of familial Alzheimer's disease (FAD) (Price and Sisodia, 1998; Larner and Doran, 2006). To date, >100 FADlinked mutations have been reported. The mechanism by which these variants cause disease is by altering $\gamma$-secretase activity in a manner that elevates the ratio of $\beta$-amyloid (A $\beta$ ) 42/40 peptides, thus enhancing nucleation and fibrillogenesis of highly amyloi-

Received May 26, 2007; revised 0ct. 9, 2007; accepted 0ct. 10, 2007

This study was supported in part by Grant-in-Aid 1859093099 for Scientific Research from the Ministry of Education, Culture, Sports, Science, and Technology, Japan, and a grant from the Research Committee on Neurodegenerative Diseases, Ministry of Health, Labor, and Welfare, Japan. We are grateful to Dr. Nobuyuki Nukina (RIKEN Brain Science Institute, Saitama, Japan) and Dr. Raphael Kopan (Washington University, St. Louis, M0) for the kind gifts of $\alpha$-synuclein and Notch $\Delta \mathrm{E}$ cDNA plasmids, respectively.

Correspondence should be addressed to Dr. Takeshi Ikeuchi, Department of Molecular Neuroscience, Brain Research Institute, Niigata University, 1 Asahimachi, Chuou-ku, Niigata 951-8585, Japan. E-mail: ikeuchi@bri.niigata-u.ac.jp.

DOI:10.1523/JNEUROSCI.4244-07.2007

Copyright $\odot 2007$ Society for Neuroscience $\quad$ 0270-6474/07/2713092-06\$15.00/0 dogenic $\mathrm{A} \beta_{42}$ (Bentahir et al., 2006; Kumar-Singh et al., 2006). Although the neuropathological features of patients with FADlinked PSEN1 mutations include the presence of senile plaques, composed primarily of $\mathrm{A} \beta$, and degenerating neurons containing hyperphosphorylated tau, the coexistence of Lewy bodies (LBs), composed primarily of $\alpha$-synuclein filaments, is becoming increasingly evident (Lippa et al., 1998; Rosenberg, 2005; Leverenz et al., 2006). In addition, the phosphorylation of $\alpha$-synuclein at Ser-129, identified as a major modification of $\alpha$-synuclein, is now considered to be the key event responsible for the formation of LBs and Lewy neurites (Fujiwara et al., 2002; Anderson et al., 2006).

We recently reported on a familial case diagnosed as having dementia with LBs (DLB) and variant AD caused by a novel $3 \mathrm{bp}$ deletion mutation in PSEN1 encoding a PS1 variant lacking a threonine residue at codon $440(\Delta \mathrm{T} 440)$ (Ishikawa et al., 2005). Neuropathological findings in this case included prominent LB and Lewy neurite formation in the substantia nigra and cerebral cortex, as well as widespread cotton-wool plaques and amyloid angiopathy. A similar widespread LB pathology in brains, fulfill- 
ing the pathological consensus criteria of the neocortical type of DLB (McKeith et al., 2005), has been observed in FAD patients with PSEN1 mutations that encode the PS1 S170F, E184D, and M233V variants (Houlden et al., 2001; Yokota et al., 2002; Snider et al., 2005). The mechanisms by which these PS1 variants cause widespread LB formation, in addition to Alzheimer pathology in the brain, have not been clarified.

To explore the possible involvement of the PS1 $\Delta$ T440 mutant in $\mathrm{A} \beta$ production and $\alpha$-synuclein metabolism, we established stable Neuro2a (N2a) mouse neuroblastoma and C6 rat glioblastoma cell lines expressing either wild-type (WT) human PS1 or the FAD-linked PS1 H163R, E280A and $\Delta \mathrm{E} 9$, and $\Delta \mathrm{T} 440 \mathrm{mu}-$ tants. We established that the expression of the FAD-linked PS1 variants leads to an elevated ratio of $\mathrm{A} \beta_{42 / 40}$ peptides in a conditioned medium; more importantly, we now demonstrate that the levels of phosphorylated $\alpha$-synuclein increase in both N2a neuroblastoma and C6 glioblastoma cells expressing the PS1 $\Delta$ T440 mutant compared with cells that express WT PS1 or the PS1 $\mathrm{H} 163 \mathrm{R}, \mathrm{E} 280 \mathrm{~A}$, and $\Delta \mathrm{E} 9$ variants. This finding is consistent with our demonstration of elevated levels of phosphorylated $\alpha$-synuclein in the detergent-resistant fraction prepared from a patient's brain with PS1 $\Delta$ T440 mutation. These observations raise the provocative suggestion that the mechanism(s) by which the PS1 $\Delta$ T440 variant causes DLB and variant AD are by enhancing the phosphorylation of $\alpha$-synuclein and the ratio of $\mathrm{A} \beta_{42 / 40}$ peptides, respectively, in the brain.

\section{Materials and Methods}

Cell culture and transfection. Mouse neuroblastoma N2a cells were maintained in 50\% DMEM and 50\% Opti-MEM (Invitrogen, Carlsbad, CA) supplemented with $5 \%$ fetal bovine serum (FBS). Rat glioblastoma C6 cells were maintained in DMEM containing 10\% FBS. PS1 $\triangle$ T440 cDNA was generated using PCR-based mutagenesis techniques and cloned into the expression vector pAG3 (Kim et al., 2001). Pooled cells that stably express WT PS1, $\Delta$ T440 mutant, or FAD-linked H163R, E280A, and $\Delta \mathrm{E} 9$ variants were generated as described previously (Ikeuchi et al., 2003). Stable cell lines were transiently transfected using Lipofectamine2000 (Invitrogen) with cDNA encoding the Swedish variant of $\beta$-amyloid precursor protein (APP) 695 (APPswe), Notch $\Delta \mathrm{E}$, or human $\alpha$-synuclein, as described previously (Iwata et al., 2001; Kim et al., 2003).

Antibodies. The polyclonal antibodies $\mathrm{PS}_{\mathrm{NT}}$ and PS1Loop were used to detect full-length PS1 and PS1 derivatives (Thinakaran et al., 1996, 1998). Full-length APP and APP-C-terminal fragment (CTF) were detected using CT15, an antisera that recognizes the $15 \mathrm{C}$-terminal amino acids of APP (Sisodia et al., 1993). Myc epitope-tagged Notch $\Delta \mathrm{E}$ derivatives including the Notch intracellular domain (NICD) were detected with 9E10 (Calbiochem, San Diego, CA) or the anti-NICD antibody (Cell Signaling Technology, Beverly, MA) that preferentially detects the activated form of Notch. The mouse monoclonal antibodies Syn-1 (BD Bioscience, San Jose, CA) and LB509 (Zymed Laboratories, South San Francisco, CA) (Baba et al., 1998) were used to detect $\alpha$-synuclein. The monoclonal antibody pSyn\#64 specifically recognizes phosphorylated $\alpha$-synuclein at serine 129 (Fujiwara et al., 2002).

Western blot analysis and $A \beta$ sandwich ELISA. Cells were solubilized using lysis buffer containing $50 \mathrm{~mm}$ Tris- $\mathrm{HCl}, \mathrm{pH}$ 7.4, $150 \mathrm{~mm} \mathrm{NaCl}, 5$ mм EDTA, $0.5 \%$ Nonidet P-40, and $0.5 \%$ sodium deoxycholate supplemented with $1 \mathrm{~mm}$ sodium orthovanadate, $5 \mathrm{~mm}$ sodium fluoride, and a protease inhibitor cocktail (Sigma-Aldrich, St. Louis, MO). The protein concentration of detergent lysates was determined using a bicinchoninic acid protein assay kit (Pierce, Rockford, IL). Cell lysates were subjected to Tris-glycine SDS-PAGE, and separated proteins were transferred to a polyvinylidene difluoride membrane (Millipore, Billerica, MA) before incubation with appropriate antibodies. Immunoreactive bands were visualized using an enhanced chemiluminescence detection system (Millipore) and semiquantified by densitometry. Two-site ELISA that specifically detects the $\mathrm{C}$ terminus of $\mathrm{A} \beta$ was performed to measure $\mathrm{A} \beta_{1-42}$ and
$\mathrm{A} \beta_{1-40}$ levels using the BNT77/BA27 and BNT77/BC05 antibodies (Wako Pure Chemical Industries, Osaka, Japan), respectively, in a conditioned medium of cells according to the instructions of the manufacturer.

Fractionation of cell extracts and frozen brain tissues. Cells were homogenized on ice in Tris-HCl buffer containing $10 \mathrm{~mm}$ Tris-HCl, pH 7.5, 1 mM EGTA, $1 \mathrm{~mm}$ dithiothreitol, and $10 \%$ sucrose with a mixture of protease and phosphatase inhibitors (Sigma-Aldrich). The obtained homogenates were centrifuged, and the resulting pellets were sequentially extracted using Tris- $\mathrm{HCl}$ buffer containing $2 \%$ SDS. Proteins from frontal cortex tissues from autopsied patients, including those with PS1 $\Delta \mathrm{T} 440$ mutation (52 years old), sporadic AD (72 years old), Parkinson's disease (70 years old), and a control individual without neurological disorder (60 years old), were extracted as described previously (Fujiwara et al., 2002). Briefly, frozen brain tissues were homogenized in a 10-fold volume of buffer A (10 mm Tris-HCl, pH 7.5, 1 mm EGTA, 1 mm dithiothreitol, and 10\% sucrose) and centrifuged. The pellets were then extracted in buffer A containing 1\% Triton X-100 and centrifuged. The resulting pellets were subsequently homogenized in buffer A containing $1 \%$ Sarkosyl, incubated for $1 \mathrm{~h}$, and centrifuged. The Sarkosyl-insoluble pellets were solubilized in $8 \mathrm{~m}$ urea buffer. After centrifugation, the supernatants were separated by SDS-PAGE and analyzed by immunoblotting.

\section{Results}

\section{Expression and metabolism of PS1 $\Delta$ T440 mutant}

We generated mouse neuroblastoma $\mathrm{N} 2 \mathrm{a}$ and rat glioblastoma C6 cell lines that stably express either human PS1 WT, the $\Delta$ T440 mutant, or the FAD-linked PS1 H163R, E280A, and $\Delta$ E9 variants. In $\mathrm{N} 2 \mathrm{a}$ cells, we observed the presence of an $\sim 43 \mathrm{kDa}$ holoprotein as well as the $\sim 27 \mathrm{kDa}$-terminal fragment (NTF) and $\sim 17 \mathrm{kDa}$ CTF of human PS1 using PS1 $1_{\mathrm{NT}}$ and PS1Loop antibodies, respectively, in detergent extracts prepared from cells expressing PS1 WT and the PS1 H163R and E280A variants (Fig. 1A, lanes 2-4). Notably, human PS1 NTF and CTF have "replaced" endogenous mouse PS1 derivatives (Fig. $1 A$, lane 1), presumably as a result of competition by the PS1 $\Delta$ T440 mutant for limiting stabilization factors (Thinakaran et al., 1997) that include nicastrin, Aph-1 (anterior pharynx defective-1), and PEN-2 (presenilin enhancer-2) (De Strooper, 2003). The difference in electrophoretic mobilities exhibited by mouse and human PS1 derivatives was reported previously (Thinakaran et al., 1996, 1997). We also observed an unprocessed, $\sim 40 \mathrm{kDa}$ PS1 $\Delta \mathrm{E} 9$ species in cells expressing the PS1 $\Delta$ E9 variant (Fig. $1 A$, lane 5), as expected (Thinakaran et al., 1996). Remarkably, and exhibiting a property shared with the PS1 $\Delta$ E9 variant, we only observed a prominent $\sim 43 \mathrm{kDa}$ species in cells expressing the PS1 $\Delta \mathrm{T} 440$ mutant and very low levels of PS1 NTF and CTF (Fig. 1A, lane 6). These results suggest that the PS $1 \Delta \mathrm{T} 440$ mutant is refractory to endoproteolytic cleavage and that expression of this mutant has replaced endogenous mouse PS1 derivatives. The entirety of these latter findings were fully recapitulated in C6 glioblastoma cells (data not shown).

The observation that the $\Delta \mathrm{T} 440$ mutant accumulates as a holoprotein could be interpreted to suggest that either unprocessed species is stable or steady-state Western blot analysis is detecting transiently overexpressed proteins. To address this issue, we treated N2a cells stably expressing WT and the $\Delta$ T440 mutant with $100 \mu \mathrm{g} / \mathrm{ml}$ cyclohexamide to block de novo protein synthesis and examined the stability of preexisting PS1-related polypeptides. The overexpressed PS1 WT holoprotein was rapidly degraded at a $t_{1 / 2}$ of $\sim 1-2 \mathrm{~h}$, as described previously (Kim et al., 2003). Conversely, the levels of the PS1 $\Delta$ T440 mutant holoproteins remained essentially unchanged over the time course, similarly to PS1 NTF observed in PS1 WT cells (Fig. 1B). 


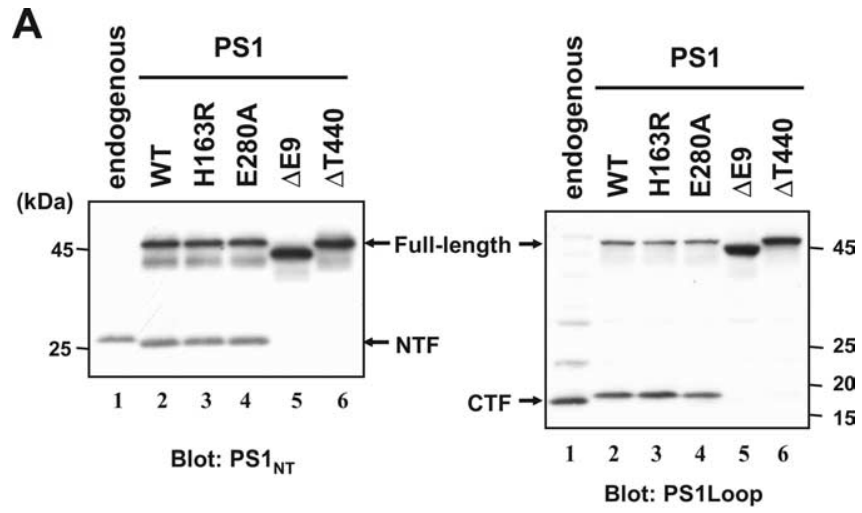

B

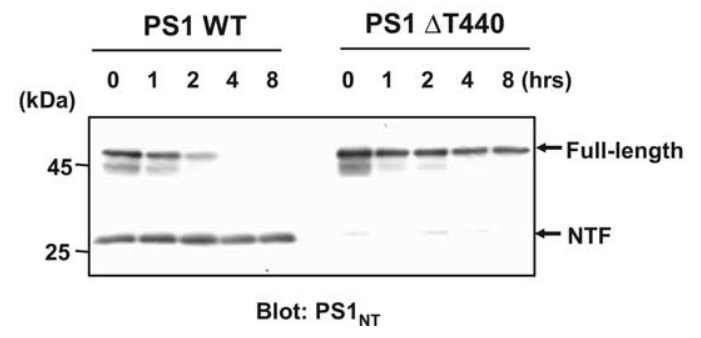

Figure 1. Expression and endoproteolysis of PS1. $A$, N2a cells were stably transfected with PS1 WT, the FAD-linked PS1 variants (H163R, E280A, and $\Delta E 9)$, or $\Delta$ T440 mutant, and the expression of PS1 derivatives was analyzed by immunoblotting using the PS1 $1_{\mathrm{NT}}$ (left) and PS1Loop (right) antibodies. Note that endoproteolysis is impaired in cells expressing the PS1 $\Delta \mathrm{T} 440$ mutant similarly to the $\Delta \mathrm{E} 9$ variant that has deletion in the cleavage sites for endoproteolysis. Molecular weight markers are shown on the lefts side in kilodaltons. $\boldsymbol{B}$, To analyze half-lives of PS1, N2a cells were treated with cyclohexamide and chased for $1-8 \mathrm{~h}$. Note that the holoproteins of the PS1 $\Delta \mathrm{T} 440$ mutant were resistant to cyclohexamide treatment similarly to the endoproteolytic fragments of PS1 WT.

$\gamma$-Secretase cleavage of APP and Notch in cells expressing PS1 $\Delta \mathrm{T} 440$ mutant

We next examined the effects of PS1 $\Delta$ T440 mutant on the $\gamma$-secretase cleavage of APP, leading to A $\beta$ production. For these studies, we transiently transfected cDNA encoding the FADlinked APPswe variant into the stable N2a cell lines, then prepared detergent extracts of cell monolayers, and collected the conditioned medium. We observed that, whereas the levels of full-length APP in both cell types appeared comparable, the levels of APP-CTFs were elevated in cells expressing the PS1 $\Delta$ T440 mutant and, to a lesser degree, in cells expressing the PS1 $\Delta \mathrm{E} 9$ variant compared with cells expressing PS1 WT (Fig. 2 A). Consistent with the elevation in the levels of APP-CTFs, the $\mathrm{A} \beta_{40}$ peptides in the conditioned medium of PS1 $\Delta$ T440 cells, as determined by quantitative sandwich ELISA, were dramatically reduced (Fig. $2 B$, top). Nevertheless, quantitative ELISA revealed that the $\mathrm{A} \beta_{42 / 40}$ ratio in the medium of PS1 $\Delta \mathrm{T} 440$-expressing cells was higher by approximately ninefold than that in the medium of PS1 WT-expressing cells (Fig. 2 B, bottom).

Consistent with the aforementioned finding that expression of PS1 $\Delta$ T440 mutant leads to accumulation of APP-CTFs and decreases $A \beta$ production, several previous studies have revealed that expression of FAD-linked PS1 variants results in an inefficient intramembranous cleavage of Notch leading to NICD generation (Song et al., 1999; Moehlmann et al., 2002). To assess $\gamma$-secretase-mediated cleavage of Notch in cells expressing the PS1 $\Delta$ T440 mutant, we transiently transfected the N2a stable cell lines with cDNA encoding a myc-tagged Notch $\Delta \mathrm{E}$ polypeptide and subjected detergent-extracted lysates to Western blot analysis with the anti-myc antibody $9 \mathrm{E} 10$ (Fig. 2C) or an antibody that
A

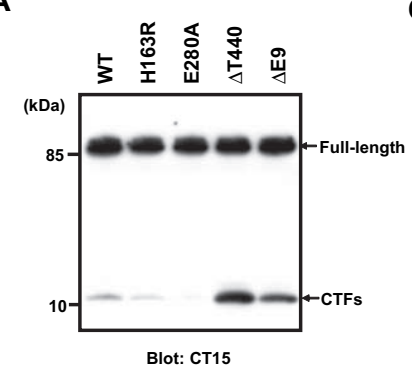

B

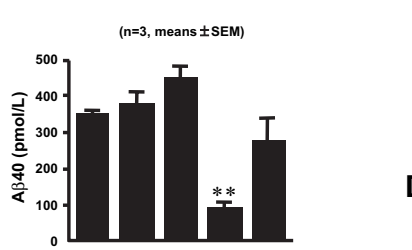

C
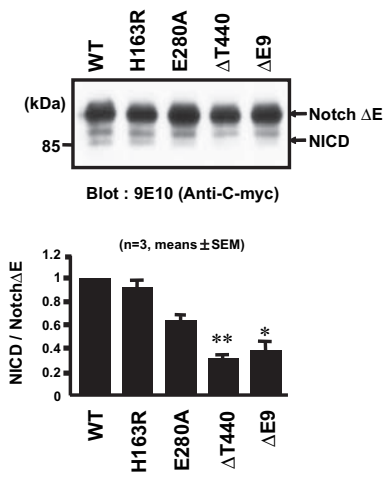

D
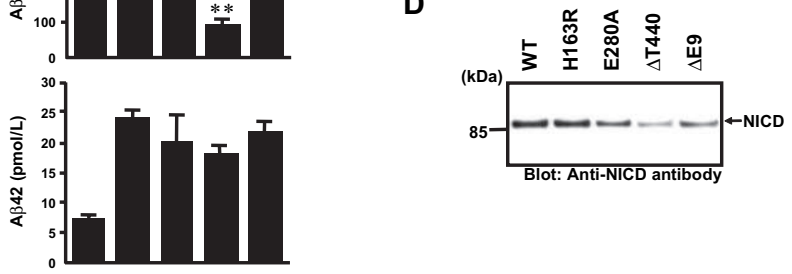

Figure 2. $\gamma$-Secretase cleavage of APP and Notch in cells expressing PS1 $\triangle T 440$ mutant. $A$, N2a cells stably expressing PS1 WT, the FAD-linked variants (H163R, E280A, and $\Delta E 9)$, or $\triangle \mathrm{T} 440$ mutant were transiently transfected with CDNA encoding APPswe, and detergentextracted lysates were evaluated by immunoblotting with the CT15 antibody. The bands corresponding to $\sim 110 \mathrm{kDa}$ full-length and $\sim 12 \mathrm{kDa}$ CTF of APP are shown. $\boldsymbol{B}$, The amounts of $A \beta_{1-40}$ and $A \beta_{1-42}$ in the conditioned medium were quantitatively analyzed by sandwich ELISA. Results from three independent experiments are shown as mean \pm SE. ${ }^{*} p<0.05$, ${ }^{* *} p<0.01$ by Tukey's test versus WT after ANOVA. C, N2a cells stably expressing PS1 WT, the FAD-linked variants ( $\mathrm{H} 163 \mathrm{R}, \mathrm{E} 280 \mathrm{~A}$, and $\Delta \mathrm{E} 9)$, or $\Delta \mathrm{T} 440$ mutant were transiently transfected with CDNA encoding Notch $\Delta$ E. Detergent-extracted lysates were analyzed by immunoblotting with the anti-myc antibody 9E10. Results of the semiquantitative analysis of NICD/Notch $\Delta \mathrm{E}$ by densitometry are shown in the bottom. Note that NICD generation is impaired in cells expressing the PS1 $\Delta \mathrm{T} 440$ mutant similarly to the $\Delta \mathrm{E} 9$ variant. ${ }^{*} p<0.05,{ }^{* *} p<0.01$ by Tukey's test versus WT after ANOVA. D, NICD generation was further analyzed using the anti-NICD antibody specific for the cleaved form of Notch. In cells expressing the PS1 $\triangle$ T440 mutant, NICD production was scarcely detectable.

recognizes a neo-epitope that specifically detects NICD (Fig. 2D). Compared with WT-expressing cells, we observed a significantly decreased production of NICD in cells expressing the PS1 $\Delta$ T440 and PS1 $\Delta$ E9 variants (Fig. 2C,D).

Increased levels of phosphorylated $\alpha$-synuclein in cells expressing PS1 $\Delta$ T440 mutant

Having established that expression of the PS1 $\Delta$ T440 mutant elevates the ratio of $\mathrm{A} \beta_{42 / 40}$ peptides in the cultured medium of the stable cell lines, we then examined the metabolism of $\alpha$-synuclein in lysates of PS1 WT, $\Delta$ T440, $\Delta$ E9, H163R, or E280A cells that were transiently transfected with cDNA encoding human $\alpha$-synuclein. Transiently transfected N2a and C6 cells were sequentially extracted with Tris- $\mathrm{HCl}$ buffer and then with $2 \%$ SDS-containing buffer, and the obtained extracts were subjected 
A

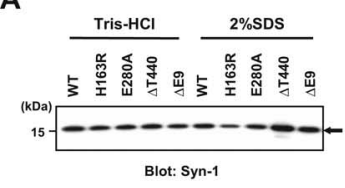

N2a

c6

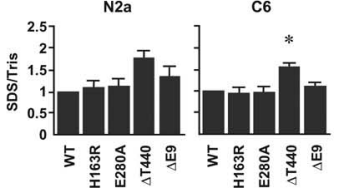

B

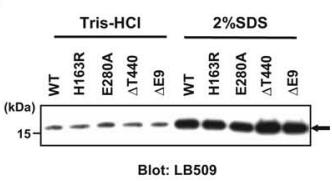

N2a

C6

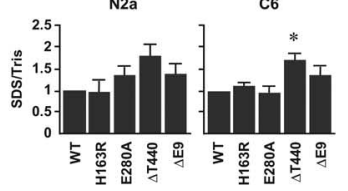

C

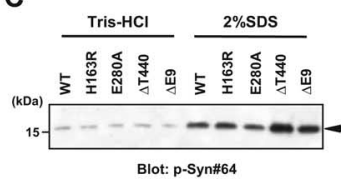

N2a

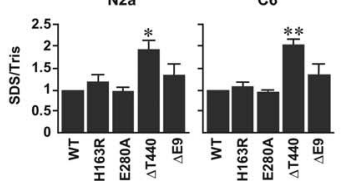

Figure 3. $\alpha$-Synuclein expression in cells expressing PS1 $\Delta \mathrm{T} 440$ mutant. $A$, N2a neuroblastoma or 6 glioblastoma cells stably expressing PS1 WT, the FAD-linked variants (H163R, E280A, and $\Delta$ E9), or $\Delta$ T440 mutant were transiently transfected with cDNA encoding human $\alpha$-synuclein. Samples sequentially extracted with Tris- $\mathrm{HCl}$ - and $2 \%$ SDS-containing buffers were separated on a $10 / 20 \%$ gradient Tris-glycine SDS-PAGE and probed with the anti- $\alpha$-synuclein antibody Syn-1. Representative results of Western blots analysis using ( 6 cell lines were shown (top). The band corresponding to the $\sim 15 \mathrm{kDa} \alpha$-synuclein monomer is indicated (arrow). The semiquantitative analysis of the expression level of $\alpha$-synuclein was performed by densitometry, and the ratio of $\alpha$-synuclein intensity in the Tris/SDS-extracted fraction was determined. Results from three independent experiments are shown as mean \pm SE. ${ }^{*} p<0.05$ by Tukey's test versus WT after ANOVA. $\boldsymbol{B}$, The samples were further blotted with the LB509 antibody that specifically recognizes human $\alpha$-synuclein (Baba et al., 1998). C, The samples were further analyzed with the anti-PSer-129 $\alpha$-synuclein antibody pSyn\#64. Note that the level of phosphorylated $\alpha$-synuclein (arrowhead) in cells expressing the PS1 $\Delta$ T440 mutant significantly increased compared with that in cells expressing WT PS1. ${ }^{*} p<0.05,{ }^{* *} p<0.01$ by Tukey's test versus WT after ANOVA.

\section{A}

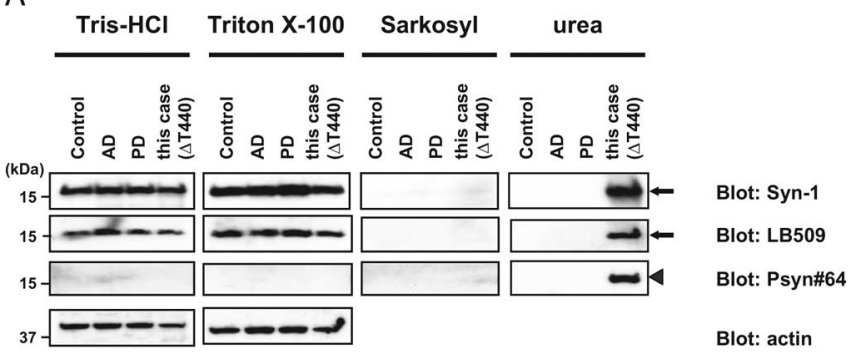

B

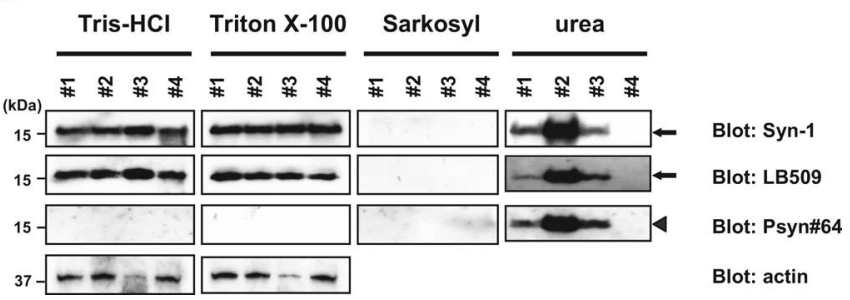

Figure 4. Aberrant accumulation of $\alpha$-synuclein in autopsied brain. $\boldsymbol{A}$, Samples extracted from brain (frontal cortex) homogenates using different detergents were run on a 10/20\% gradient Tris-glycine SDS-PAGE system and subjected to immunoblotting using the $\alpha$-synuclein antibodies Syn-1, LB509, and pSyn\#64. In the urea-extracted fraction, the monomer $\alpha$-synuclein migrating at $\sim 15 \mathrm{kDa}$ (arrow), which was reactive to the antiphosphorylated $\alpha$-synuclein antibody pSyn\#64 (arrowhead), substantially accumulated only in the brain of the patient with the PS1 $\Delta$ T440 mutation. $\boldsymbol{B}$, Samples were extracted from various regions of the patient's brain with PS1 $\Delta$ T440 mutation, including the frontal cortex (\#1), parahippocampal gyrus (\#2), thalamus (\#3), and cerebellum (\#4). The level of $\alpha$-synuclein accumulation was highest in the urea-extracted fraction prepared from the parahippocampal gyrus (\#2), followed by the thalamus (\#3) and the frontal cortex (\#1). The accumulation of $\alpha$-synuclein was not observed in the urea-extracted fraction prepared from the cerebellum.

to Western blot analysis with two $\alpha$-synuclein-specific antibodies Syn-1 and LB509.

Although the levels of $\alpha$-synuclein were comparable in the Tris-buffer-extracted fractions prepared from the these cell types, we observed that the levels of $\alpha$-synuclein were higher in the SDS-extracted fraction of cells expressing the PS $1 \Delta$ T440 mutant than in cells expressing WT PS1 (Fig. $3 A, B)$. Importantly, the levels of $\alpha$-synuclein in the SDS-extracted fraction from cells expressing the PS1 H163R and E280A variants, which are not associated with LB formation in the autopsied brains of patients expressing these mutants (Lippa et al., 1998), were apparently unchanged compared with cells expressing WT PS1. In view of the findings that phosphorylation of $\alpha$-synuclein at Ser-129 is the principal modification of $\alpha$-synuclein in LBs (Fujiwara et al., 2002; Anderson et al., 2006), we then examined the levels of phosphorylated $\alpha$-synuclein with a highly specific anti-PSer-129 antibody (pSyn\#64). We show that the levels of Ser-129-phosphorylated $\alpha$-synuclein is significantly increased in the SDSextracted fraction prepared from cells expressing the PS1 $\Delta$ T440 mutant and, to a lesser but statistically insignificant extent, in cells expressing the $\Delta$ E9 variant (Fig. $3 C$ ). Notably, we also observed low levels of phosphorylated $\alpha$-synuclein in cells expressing WT PS1, a finding consistent with previous reports showing that $\alpha$-synuclein is subject to low levels of phosphorylation after its overexpression in mammalian cells (Smith et al., 2005). Together, these observations indicate that the expression of the PS1 $\Delta$ T440 mutant enhances the accumulation of phosphorylated $\alpha$-synuclein in the detergent-resistant cellular fraction.

\section{Aberrant accumulation of phosphorylated $\alpha$-synuclein in brain of a patient with PSEN1 $\triangle \mathrm{T} 440$ mutation}

To examine whether $\alpha$-synuclein accumulation is observed in the detergent-resistant fraction in vivo, we sequentially extracted homogenates from the frontal cortices of a control subject without a neurological disorder and brains of patients with $\mathrm{AD}$, Parkinson's disease, and PS1 $\Delta$ T440 mutation and subjected these samples to Western blot analysis. We observed comparable levels of $\alpha$-synuclein in the Tris- or Triton X-100-extracted fractions, as determined using the anti- $\alpha$-synuclein antibodies Syn- 1 and LB509 (Fig. 4A). Extraction of the Tris- and Triton X-100resistant pellet with the nonionic detergent Sarkosyl failed to release detectable amount of $\alpha$-synuclein. Conversely, extraction of the detergent-insoluble pellet with $8 \mathrm{M}$ urea revealed the presence of $\alpha$-synuclein specifically in the brain of the patient with the PSEN1 $\triangle \mathrm{T} 440$ mutation. More importantly, immunoblot analysis using the anti-PSer-129 antibody revealed the presence of high levels of Ser-129-phosphorylated $\alpha$-synuclein in the ureaextracted fraction from the PSEN1 $\triangle \mathrm{T} 440$ patient brain compared with the controls (Fig. $4 A$ ). We then prepared samples from various regions of the brain of the patient with the PS1 $\Delta$ T440 mutation. As expected, phosphorylated $\alpha$-synuclein was aberrantly accumulated in the urea-extracted fraction; the parahippocampal regions showed the highest level of accumulation, followed by the frontal cortex and the thalamus, but phosphorylated $\alpha$-synuclein was scarcely detected in the cerebellum (Fig. $4 B)$. Collectively, these results suggest that the presence of PS1 $\Delta \mathrm{T} 440$ mutation promotes the aberrant accumulation of phosphorylated $\alpha$-synuclein in the detergent-resistant fraction in vivo. 


\section{Discussion}

We recently reported on a familial case diagnosed as having DLB and variant $\mathrm{AD}$ and identified a novel 3 bp deletion mutation in the PSEN1 gene encoding a PS1 variant lacking a threonine residue at codon $440(\Delta \mathrm{T} 440)$ (Ishikawa et al., 2005). It is of note that this patient was clinically diagnosed as having L-3,4dihydroxyphenylalanine-responsive juvenile parkinsonism with dementia. Remarkably, we observed prominent LB and Lewy neurite formation in the substantia nigra and cerebral cortex, as well as widespread cotton-wool plaques and amyloid angiopathy. In the present report, we investigate the potential mechanisms by which expression of the PS1 $\Delta$ T440 mutant causes LB formation, in addition to the $\mathrm{AD}$ pathology, and now offer several important insights.

First, we demonstrate that, in stable cell lines of neuronal or non-neuronal origin, the PS1 $\Delta$ T440 mutant fails to undergo endoproteolytic cleavage and that the unprocessed molecule exhibits a half-life no different from that observed for the PS1 derivatives generated from WT PS1. These findings strongly suggest that $\Delta \mathrm{T} 440$ holoproteins are incorporated into stable highmolecular-weight PS complexes that include nicastrin, Aph-1, and PEN-2 (Kim et al., 2003; Takasugi et al., 2003). The lack of endoproteolysis of PS1 holoprotein is not unique to this PS1 $\Delta \mathrm{T} 440$ mutant, because the FAD-linked C410Y (Sherrington et al., 1995) and PS1 $\Delta$ E9 (Thinakaran et al., 1996) polypeptides also fail to undergo endoproteolytic cleavage and accumulate as stable holoproteins. Second, we demonstrate that the expression of the PS1 $\Delta$ T440 mutant leads to a marked elevation in the ratio of $\mathrm{A} \beta_{42 / 40}$ peptides in the conditioned medium of stable cell lines. Mechanistically, evidence has accrued to suggest that elevations in $\mathrm{A} \beta_{42 / 40}$ peptide ratio enhances the nucleation and fibrillogenesis of pathogenic $A \beta_{42}$ peptides, events that are otherwise compromised by the presence of high levels of secreted $A \beta_{40}$ peptides (Bentahir et al., 2006; Deng et al., 2006; Kumar-Singh et al., 2006; Kim et al., 2007). Third, we demonstrate that transiently expressed $\alpha$-synuclein accumulates at high levels in 2\% SDSextracted fraction prepared from cells expressing the PS1 $\Delta \mathrm{T} 440$ mutant compared with cells expressing WT PS1 or the FADlinked PS1 H163R and E280A variants that do not lead to LB formation in the brain. Finally, we observed that Ser-129phosphorylated $\alpha$-synuclein is present in 2\% SDS-extracted fraction from cells expressing WT PS1, but the levels of these species are significantly elevated in extracts from PS1 $\Delta$ T440 cells. Indeed, we demonstrate that high levels of Ser-129-phosphorylated $\alpha$-synuclein are present in the detergent-resistant fraction prepared from the brain of a patient with PS1 $\Delta$ T440 mutation. These findings suggest that expression of PS1 $\Delta$ T440 induces the aberrant accumulation of highly insoluble, Ser-129phosphorylated $\alpha$-synuclein, leading to the formation of LBs and Lewy neurites.

The mechanism(s) by which the PS1 $\Delta 440$ variant enhances Ser-129 phosphorylation is not presently understood. Previous studies have shown that casein kinases 1 and 2 and G-proteincoupled receptor kinases can phosphorylate synuclein in vitro (Okochi et al., 2000; Arawaka et al., 2006). However, there is limited information about the role of PS1 in regulating the enzymatic function of these kinases in vivo. Conversely, studies have revealed that PS1 associates with glycogen synthase kinase (GSK-3) (Takashima et al., 1998; Tesco and Tanzi, 2000), and expression of FAD-linked PS1 in mammalian cells has been shown to increase GSK-3 activity (Takashima et al., 1998; Pigino et al., 2003; Baki et al., 2004). Future studies will be required to evaluate the effects of the PS1 $\Delta$ T440 mutant on GSK-3 activity.

The relationship between the observed increases in $\mathrm{A} \beta_{42 / 40}$ ratio and phosphorylated $\alpha$-synuclein level is far from understood. However, it is of interest to note that the patient with PS1 $\Delta$ T440 mutation exhibited cotton-wool plaques composed mainly of $\mathrm{A} \beta_{42}$ and lacking a congophilic dense core and plaquerelated neuritic pathology. Double transgenic mice expressing APP and $\alpha$-synuclein showed more $\alpha$-synucleinimmunopositive neuronal inclusions than single transgenic mice expressing only $\alpha$-synuclein (Masliah et al., 2001). Notwithstanding these interesting correlations, it would be premature to conclude that elevation in $\mathrm{A} \beta_{42 / 40}$ ratio solely contributes to the development of LB pathology, because these lesions have not been reported as a significant neuropathological feature in the brains of the vast majority of patients harboring FAD-linked PSEN1 or PSEN2 mutations. In any event, our findings that the expression of the PS1 $\Delta$ T440 mutant leads to an enhanced accumulation of Ser-129-phosphorylated $\alpha$-synuclein in both cultured cells and a patient brain as well as elevated $\mathrm{A} \beta_{42 / 40}$ ratios now offer new opportunities for investigating the underlying molecular mechanisms by which A $\beta$ modulates $\alpha$-synuclein accumulation in LBs.

\section{References}

Anderson JP, Walker DE, Goldstein JM, de Laat R, Banducci K, Caccavello RJ, Barbour R, Huang J, Kling K, Lee M, Diep L, Keim PS, Shen X, Chataway T, Schlossmacher MG, Seubert P, Schenk D, Sinha S, Gai WP, Chilcote TJ (2006) Phosphorylation of Ser-129 is the dominant pathological modification of $\alpha$-synuclein in familial and sporadic Lewy body disease. J Biol Chem 281:29739-29752.

Arawaka S, Wada M, Goto S, Karube H, Sakamoto M, Ren CH, Koyama S, Nagasawa H, Kimura H, Kawanami T, Kurita K, Tajima K, Daimon M, Baba M, Kido T, Saino S, Goto K, Asao H, Kitanaka C, Takashita E, et al. (2006) The role of G-protein-coupled receptor kinase 5 in pathogenesis of sporadic Parkinson's disease. J Neurosci 26:9227-9238.

Baba M, Nakajo S, Tu PH, Tomita T, Nakaya K, Lee VM-Y, Trojanowski JW, Iwatsubo T (1998) Aggregation of $\alpha$-synuclein in Lewy bodies of sporadic Parkinson's disease and dementia with Lewy bodies. Am J Pathol 152:879-884.

Baki L, Shioi J, Wen P, Shao Z, Schwarzman A, Gama-Sosa M, Neve R, Robakis NK (2004) PS1 activates PI3K thus inhibiting GSK-3 activity and tau overphosphorylation: effects of FAD mutations. EMBO J 23:2586-2596.

Bentahir M, Nyabi O, Verhamme J, Tolia A, Horre K, Wiltfang J, Esselmann H, De Strooper B (2006) Presenilin clinical mutations can affect $\gamma$-secretase activity by different mechanisms. J Neurochem 96:732-742.

De Strooper B (2003) Aph-1, Pen-2, and Nicastrin with presenilin generate an active $\gamma$-secretase complex. Neuron 38:9-12.

Deng Y, Tarassishin L, Kallhoff V, Peethumongsin E, Wu L, Li Y-M, Zheng H (2006) Deletion of presenilin 1 hydrophilic loop sequence leads to impaired $\gamma$-secretase activity and exacerbated amyloid pathology. J Neurosci 26:3845-3854.

Fujiwara H, Hasegawa M, Dohmae N, Kawashima A, Masliah E, Goldberg MS, Shen J, Takio K, Iwatsubo T (2002) $\alpha$-Synuclein is phosphorylated in synucleinopathy lesions. Nat Cell Biol 4:160-164.

Houlden H, Crook R, Dolan RJ, McLaughlin, Revesz T, Hardy J (2001) A novel presenilin mutation (M233V) causing very early onset Alzheimer's disease with Lewy bodies. Neurosci Lett 313:93-95.

Ikeuchi T, Dolios G, Kim SH, Wang R, Sisodia SS (2003) Familial Alzheimer Disease-linked presenilin 1 variants enhance production of both $\mathrm{A} \beta 1-40$ and $A \beta 1-42$ peptides that are only partially sensitive to a potent aspartyl protease transition inhibitor of " $\gamma$-secretase". J Biol Chem 278:7010-7018.

Ishikawa A, Piao YS, Miyashita A, Kuwano R, Onodera O, Ohtake H, Suzuki M, Nishizawa M, Takahashi H (2005) A mutant PSEN1 causes dementia with Lewy bodies and variant Alzheimer's disease. Ann Neurol 57:429-434.

Iwata A, Miura S, Kanazawa I, Sawada M, Nukina N (2001) $\alpha$-Synuclein 
forms a complex with transcription factor Elk-1. J Neurochem 77:239-252.

Kim J, Onstead L, Randle S, Price R, Smithson L, Zwizinski G, Dickson DW, Golde T, McGowan E (2007) $\mathrm{A} \beta_{40}$ inhibits amyloid deposition in vivo. J Neurosci 27:627-633.

Kim SH, Ikeuchi T, Yu C, Sisodia SS (2003) Regulated hyperaccumulation of presenilin-1 and the " $\gamma$-secretase" complex. J Biol Chem 278:33992-34002.

Kim SH, Leem JY, Lah JJ, Slunt HH, Levey AI, Thinakaran G, Sisodia SS (2001) Multiple effects of aspartate mutant presenilin 1 on the processing and trafficking of amyloid precursor protein. J Biol Chem 276:43343-43350.

Kumar-Singh S, Theuns J, Van Broeck B, Pirici D, Vennekens K, Corsmit E, Cruts M, Dermaut B, Wang R, Van Broeckhoven C (2006) Mean ageof-onset of familial Alzheimer disease caused by presenilin mutations correlates with both increased $\mathrm{A} \beta 42$ and decreased $\mathrm{A} \beta 40$. Hum Mutation 27:686-695.

Larner AJ, Doran M (2006) Clinical phenotypic heterogeneity of Alzheimer's disease associated with mutations of the presenilin-1 gene. J Neurol 253:139-158.

Leverenz JB, Fishel MA, Peskind ER, Montine TJ, Nochlin D, Steinbart E, Raskind MA, Schellenberg GD, Bird TD, Tsuang D (2006) Lewy body pathology in familial Alzheimer disease: evidence for disease- and mutation-specific pathologic phenotype. Arch Neurol 63:370-376.

Lippa CF, Fujiwara H, Mann DA, Giasson B, Baba M, Schmidt ML, Nee LE, O'Connell BO, Pollen DA, St. George-Hyslop P, Ghetti B, Nochlin D, Bird TD, Cairns NJ, Lee VM-Y, Iwatsubo T, Trojanowski J (1998) Lewy bodies contain altered $\alpha$-synuclein in brains in many familial Alzheimer's disease patients with mutations in presenilin and amyloid precursor genes. Am J Pathol 153:1365-1370.

Masliah E, Rockenstein E, Veinbergs I, Sagara Y, Mallory, Hashimoto M, Mucke L (2001) $\beta$-Amyloid peptides enhance $\alpha$-synuclein accumulation and neuronal deficits in a transgenic mouse model linking Alzheimer's disease and Parkinson's disease. Proc Natl Acad Sci USA 98:12245-12250.

McKeith IG, Dickson DW, Lowe J, Emre M, O’Brien JT, Feldman H, Cummings J, Duda JE, Lippa C, Perry EK, Aarsland D, Arai H, Ballard CG, Boeve B, Burn DJ, Costa D, Del Ser T, Dubois B, Galasko D, Gauthier S, et al. (2005) Diagnosis and management of dementia with Lewy bodies: third report of the DLB consortium. Neurology 65:1863-1872.

Moehlmann T, Winkler E, Xia X, Edbauer D, Murrell J, Capell A, Kaether C, Zheng H, Ghetti B, Haass C, Steiner H (2002) Presenilin-1 mutations of leucine 166 equally affect the generation of the Notch and APP intracellular domains independent of their effect on $\mathrm{A} \beta 42$ production. Proc Natl Acad Sci USA 99:8025-8030.

Okochi M, Walter J, Koyama A, Nakajo S, Baba M, Iwatsubo T, Meijer L, Kahle PJ, Haass C (2000) Constitutive phosphorylation of the Parkinson's disease associated $\alpha$-synuclein. J Biol Chem 275:390-397.

Pigino G, Morfini G, Pelsman A, Mattson MP, Brady ST, Busciglio J (2003) Alzheimer's presenilin 1 mutations impair kinesin-based axonal transport. J Neurosci 23:4499-4508.
Price DL, Sisodia SS (1998) Mutant genes in familial Alzheimer's disease and transgenic mice. Annu Rev Neurosci 21:479-505.

Rosenberg RN (2005) New presenilin 1 mutation with Alzheimer disease with Lewy bodies. Arch Neurol 62:1808.

Sherrington R, Rogaev EI, Liang Y, Rogaeva EA, Levesque G, Ikeda M, Chi H, Lin C, Li G, Holman K, Tsuda T, Mar L, Foncin JF, Bruni AC, Montesi P, Sorbi S, Rainero I, Pinessi L, Nee L, Chumakov I, et al. (1995) Cloning of a gene bearing missense mutations in early-onset familial Alzheimer's disease. Nature 375:754-760.

Sisodia SS, Koo EH, Hoffman PN, Perry G, Price DL (1993) Identification and transport of full-length amyloid precursor proteins in rat peripheral nervous system. J Neurosci 13:3136-3142.

Smith WW, Margolis RL, Li X, Troncoso JC, Lee MK, Dawson VL, Dawson TM, Iwatsubo T, Ross CA (2005) $\alpha$-Synuclein phosphorylation enhances eosinophilic cytoplasmic inclusion formation in SH-SY5Y cells. J Neurosci 25:5544-5552.

Snider BJ, Norton J, Coats MA, Chakraverty S, Hou CE, Jervis R, Lendon CL, Goate AM, McKeel DW, Morris JC (2005) Novel presenilin 1 mutation (S170F) causing Alzheimer disease with Lewy bodies in the third decade of life. Arch Neurol 62:1821-1830.

Song W, Nadeau P, Yuan M, Yang X, Shen J, Yankner BA (1999) Proteolytic release and nuclear translocation of Notch-1 are induced by presenilin-1 and impaired by pathogenic presenilin-1 mutations. Proc Natl Acad Sci USA 96:6959-6963.

Takashima A, Murayama M, Murayama O, Kohno T, Honda T, Yasutake K, Nihonmatsu N, Mercken M, Yamaguchi H, Sugihara S, Wolozin B (1998) Presenilin 1 associates with glycogen synthase kinase-3beta and its substrate tau. Proc Natl Acad Sci USA 95:9637-9641.

Takasugi N, Tomita T, Hayashi I, Tsuruoka M, Niimura M, Takahashi Y, Thinakaran G, Iwatsubo T (2003) The role of presenilin cofactors in the $\gamma$-secretase complex. Nature 422:438-441.

Tesco G, Tanzi RE (2000) GSK3 beta forms a tetrameric complex with endogenous PS1-CTF/NTF and beta-catenin. Effects of the D257/D385A and FAD-linked mutations. Ann NY Acad Sci 920:227-232.

Thinakaran G, Borchelt DR, Lee MK, Slunt HH, Spitzer L, Kim G, Ratovitsky T, Davenport F, Nordstedt C, Seeger M, Hardy J, Levey AI, Gandy SE, Jenkins NA, Copeland NG, Price DL, Sisodia SS (1996) Endoproteolysis of presenilin 1 and accumulation of processed derivatives in vivo. Neuron 17:181-190.

Thinakaran G, Harris CL, Ratovitski T, Davenport F, Slunt HH, Price DL, Borchelt DR, Sisodia SS (1997) Evidence that levels of presenilins (PS1 and PS2) are coordinately regulated by competition for limiting cellular factors. J Biol Chem 272:28415-28422.

Thinakaran G, Regard JB, Bouton CM, Harris CL, Price DL, Borchelt DR, Sisodia SS (1998) Stable association of presenilin derivatives and absence of presenilin interaction with APP. Neurobiol Dis 4:438-453.

Yokota O, Terada S, Ishizu H, Ujike H, Ishihara T, Nakashima H, Yasuda M., Kitamura Y, Uéda K, Checler F, Kuroda S (2002) NACP/ $\alpha$-synuclein, NAC, and $\beta$-amyloid pathology of familial Alzheimer's disease with the E184D presenilin-1 mutation: a clinicopathological study of two autopsy cases. Acta Neuropathol 104:637-648. 